\title{
Reflections on the Construction of Humanities Curriculum System of Science and Engineering Specialty in Colleges and Universities
}

\author{
Liping Dong \\ Henan University of Animal Husbandry and Economy, Zhengzhou, Henan, China, 450046
}

Keywords: Reflections, Construction, Humanities Curriculum System, Science and Engineering Specialty, Colleges and Universities

Abstract. The talents cultivated by the universities of science and technology have made great contributions to the development of our country, but in the process of science and engineering education, we attach great importance to the cultivation of scientific literacy, lack of humanistic concern. Some students never participate in the relevant activities of cultural quality education, which is extremely detrimental to the students. The science and engineering colleges and universities must change this situation, so as to meet the needs of student development.

\section{Introduction}

With the rapid development of human social science and technology, productivity levels are increasing, the world economy has achieved an unprecedented prosperity. Human use of science and technology to the endless natural request has far exceeded the capacity of nature, resulting in environmental pollution and energy crisis in nature, but also led to the continuous decline of moral ethics. People gradually recognize the one-sided emphasis on the shortcomings of the development of science and technology, continue to think and seek ways to solve the problem began to pay attention to the guiding role of the humanities. Therefore, the problem of humanities quality in the training began to be closely watched.

Since the founding of the PRC, China's planned economic system, the only purpose of higher education is to serve economic construction, long-term implementation of highly specialized education and re-literate, humanistic quality education is far lower than the scientific education, A large extent, led to the lower level of humanistic quality of college students, hindering the improvement of the overall quality of students. A number of surveys show that the current situation of humanistic quality education of science and engineering students in China is worrying and this phenomenon has aroused the concern and attention of the education departments and many people of insight, which also sounded the humane quality education of science and engineering universities in China.

\section{The Characteristics of Humanistic Quality Education}

Natural sciences can only be repeated in the laboratory, and the humanities can only history, life and life as an experimental site, which determines the understanding of human knowledge theory, the concept of human culture and shaping the combination of self. First of all, only the recognized knowledge can constitute the basic accumulation of individual human knowledge, in-depth understanding of the level can make the accumulation of knowledge into physical and mental reality; Second, the recognition is an important way to open up the boundaries between disciplines, It can get through the professional interval, a deep grasp of the object being studied, through the expression of different expression of their own ideas, and ultimately become a professional extension of Xinjiang who is not dead. Again, the recognition helps to play the creative. The education of humanistic quality education can only discover valuable problems only by sneaking into the depths of the soul, so as to provide sufficient motivation for the next step of learning and research. It can make thinking out of the inertia of the track, get true originality.

The subject of humanistic quality education directly determines the continuity of the educational process. Humanistic quality education cannot be once and for all, but cannot be achieved overnight. 
Humanistic quality education will always be in the unfinished state. If the university does not pay attention to the humanistic quality education as a long-term project to implement, students do not pay attention to their own human accumulation and it will inevitably lead to the degradation of its human qualities.

Humanistic quality education to promote human nature, thinking and exploring the moral, ideals, values, rich in emotion, is a very humane education. True humanistic quality education cultivates students' positive health, rich and delicate emotions. It directs people to find the original state of human being, which is linked with the character of defying frustration, facing difficulties, positive enterprising, self-esteem and self-confidence. People can be from the excellent history, literature and works of art in the sentiment to the author's emotional tendencies, constantly close to the good and the beautiful, to abandon false ugly.

Individual humanistic knowledge acquisition can help to enhance its humanistic spirit, but it cannot be transformed into beneficial humanistic practical ability. The humanistic knowledge into a long-lasting sustainable practice of human ability requires repeated practice. To encourage the practice of educational objects, cultivate a variety of educational objects of human ability to practice, in many ways to strengthen their sense of social responsibility, in order to truly achieve the goal of humanistic quality education. Schools should attach great importance to a variety of social practice and community activities, part of them into the teaching plan, strict examination system, so that social practice give full play to its role in the process of humanistic quality education.

\section{The Significance of Humanities Education for Science and Engineering Students}

Enrich Students' Knowledge Base. As we all know, China's examination-oriented education model led to the implementation of liberal arts teaching in secondary schools. Most of the science and engineering college students in the middle school stage did not get the humanistic quality of systematic training, resulting in their humanistic quality is not high. Some students of science and engineering have a low level of language and write articles that do not work well. Even some graduates cannot write project reports and engineering design manuals in fluent and rational language. Writing language can hardly reflect objective reality.

Improve the Thinking Level of Students. Under the influence of the traditional teaching mode, China's university education still adopts the teaching method of "teacher speaks, students listen". Most of the teachers are trained by the traditional education of talent, which led to their knowledge is often taught only to teach students "what", and will not inspire students to think about "why", can only let students passively accept, But cannot let students take the initiative to discover the problem, solve the problem, ignoring the enthusiasm of the students, initiative and participation. On the actual situation, China's science and engineering college students pay more attention to students' professional knowledge and skills to learn and ignore their own thinking ability.

Cultivate Students' Healthy Personality. The technological revolution in the world has provided a powerful impetus to the development of human society. Its influence is generally positive, but also brings some negative effects. Chinese Academy of Sciences Yang Shuzi summed it up as "five fine five wasteland", that is "skilled in science, shortage of people in school; skilled in computer, shortage of human brain; skilled in network conditions, shortage of human; skilled in commodities, shortage To strengthen the humanities quality education of science and engineering students, is conducive to foster its scientific humanitarian thinking and social responsibility. The development of science and technology needs to be guided by the humanistic spirit, in order to give full play to positive effects, eliminate its negative effects. No matter how the rapid development of science and technology cannot at the expense of the perfection of the cost of personality. Because only the pursuit of the perfect personality to make students learn to understand themselves and understand the value of life, personality is not perfect to make people fully developed wish fulfilled. 


\section{The Principle of Constructing Humanities Curriculum System of Science and Engineering Specialty in Colleges and Universities}

The construction of humanities quality education curriculum system for science and engineering students should follow certain principles, so as to avoid randomness and blindness as far as possible. I believe that the following principles should be followed:

The relevance of curriculum construction has two meanings. We emphasize the integration of science and humanities, but cannot go to the other extreme, with a large number of humanities curriculums to squeeze or replace the content of science courses, to adhere to the principle of less and less, without significant increase in school hours under the premise, the integration and penetration to achieve the goal of education. Humanities quality education is directly related to the overall development of college students, curriculum should be able to cut shortcomings, to seize the key points, from the emotional, emotional, and cultural aspects of the humanistic quality of the students is the key to the 21 st century teaching reform, At the same time, we should respect the interests of college students, based on a wide range of research to open some of the existing humanistic meanings, but also by the students generally welcomed by the students, students will have a lot of emotion, enrich the spiritual life, elegant aesthetic taste; Of the humanities curriculum, to carry out some of their characteristics in line with the humanities activities.

The Construction of Humanistic Quality Education Curriculum System for Science and Engineering Students Must Establish the Concept of System. On the one hand, humanistic quality education itself is a system engineering, involving all aspects of school work and school management departments, through unified planning, science and engineering students to achieve humane quality education systematization, standardization and institutionalization. On the other hand, the curriculum of humanistic quality education is a multidimensional system, which covers many aspects such as politics, economy, history, law, literature and art. Only by establishing systematic view can we avoid the singleness and one-sidedness of course setting. Humanities and social science courses in science and engineering as a whole professional education programs and curriculum arrangements, professional education curriculum structure should be part of the system or subsystems, and the overall curriculum system should be coordinated. The curriculum can not only pursue the development of discipline, but also should focus on the overall goal of humanistic education, and reflect the interdisciplinary interpenetration and integration. In accordance with the common goal of humanistic education, we should choose and set up the curriculum so that the courses can complement each other, complement each other, support each other and form the overall effect.

Because of the difference of environment, the difference of subjects and the effect of exam-oriented education in middle school, and the yearly enrollment of colleges and universities, the humane qualities of science and engineering students are obviously different. Therefore, our humanistic curriculum should be divided into two levels: First, basic knowledge and basic ability to popularize, in order to improve the overall cultural quality of college students; the second is based on the popularity of a certain theoretical depth and methodological significance of the course, to guide students to further deepen the knowledge, cultivate sentiments, sublimation personality, insight Cultural spirit, enhance cultural heritage.

\section{The Content Composition of Humanities Curriculum System of Science and Engineering Specialty in Colleges and Universities}

The Subject Curriculum System. Subject course system itself is a complex system. It should be composed of many large disciplinary groups and each subject group by the number of disciplines, each subject is divided into different professional and direction. Therefore, in the humanistic quality education curriculum system, should involve as many subject areas as possible. We can design the corresponding humanities curriculum module according to the contents and disciplines of humanistic quality education. Each module is composed of several courses, and some links are formed between the modules, so that the curriculum system highlights the overall function. Of course, due to time 
constraints, we cannot exhaust all courses, but each module to one or two core courses as a compulsory, while the need to set the professional limit and optional courses, as far as possible a more comprehensive reflection of college humanities Quality requirements, in order to achieve the basic objectives of education.

The Activity Curriculum System. The rich cultural connotations of various cultural activities can help students develop the spirit of cooperation, competition and innovation, help students learn to explore, learn to cooperate, learn to communicate, but also conducive to students' public accomplishment, normative consciousness and self-discipline to cultivate. To this end, I believe that the humanities curriculum is also a humanistic quality education curriculum system is a very important content, it is an extension of the curriculum and useful supplement for the cultivation of humanities and science and engineering students and the formation of the humanities has indispensable effect.

The Environmental Curriculum System. Humanistic environment course is also an important content and link in the curriculum system of humanistic quality education. A good humanistic environment can enlighten the students in the atmosphere of "moistening things and silently", cultivating the character and improving the quality, Spirit to sublimation. The environmental curriculum of humanistic quality education includes three aspects: 1. Material environment, such as campus architecture and facilities, campus design and landscaping, classroom layout, cultural window and so on. An important way to carry out humanistic quality education for science and engineering students is to build a rich humanistic education environment by further promoting the construction of campus culture. 2, The institutional environment, such as policy support, organizational security, teacher protection, financial security, security hours, evaluation mechanism, a sound institutional environment, human quality education is the implementation and implementation of important support. 3, The spirit environment, such as the history of the school tradition, human atmosphere, the pursuit of ideals, academic atmosphere, teacher-student relationship. The spiritual environment is the deep core of humanistic education environment curriculum and the most cohesive, centripetal force and vitality humanistic quality. It embodies the common values, ideals, beliefs and sentiments of campus groups most profoundly and stably.

\section{Conclusion}

The construction of humanities quality education course system for science and engineering students is a systematic project. We should stand on the commanding height of the times, combine the logical structure and development history, knowledge application and method infiltration, explicit curriculum and hidden curriculum, value timeliness and the content relevance, carry out humanistic quality education in a systematic manner to improve the effectiveness of education.

\section{Acknowledgements}

Fund Project: Henan Education Department Major Projects: "New Undergraduate Humanization Management Practice and Research"(17A880008)

\section{References}

[1] Jia Xinzhang, Li Jingyuan. Education and Occupation, Vol. 6 (2014) No 53, p.25-26

[2] Peng Sue, Wang Yunhui. Continuing Education Research, Vol. 12 (2015) No 27, p.74-76

[3] Qian Xiyuan, Jing Jianfen. Beijing Education, Vol. 30 (2014) No 19, p.144-145

[4] Wang Kuailiang. Journal of Jiangxi Education, Vol. 29 (2008) No 27, p.21-23

[5] Zhang Gongxu, Sun Jing. Educational Development Research, Vol. 8 (2013) No 27, p.57-60 